\title{
Stress fractures of the pubic rami in rheumatoid arthritis
}

\author{
A H Isdale
}

\begin{abstract}
Objective-To draw attention to and detail the features of stress factures of the pubic rami in patients with rheumatoid arthritis (RA).

Methods-Twenty two cases were collected prospectively over a four year period from patients undergoing active rheumatological surveillance in Leeds. Both old and new fractures were included. Information was obtained from the patients, clinical notes, and radiological investigations.
\end{abstract}

Results-All patients were women (mean age $68 \cdot 1$ years) with longstanding (mean disease duration $24 \cdot 2$ years) seropositive RA. Nineteen $(86 \%)$ were receiving regular prednisolone treatment and all patients had radiological evidence of osteoporosis, with vertebral crush fractures in $10(63 \%)$ of the 16 who had vertebral $x$ ray examination. There was no biochemical evidence of osteomalacia. Nineteen $(86 \%)$ presented with pain in the low back, groin, or hip and three were asymptomatic. Pain developed gradually in seven with an acute onset in the remainder. Six gave a history of a fall but only seven were $x$ rayed at the onset of symptoms and initial radiographs were negative in five of these. In eighteen the fracture had either minimal or no effect on their mobility. Fractures affected all four pubic rami and in four all four were fractured. All but one patient (who had multiple fractures) made an uneventful recovery over two to four weeks with conservative management.

Conclusions-Stress fractures of the pubic rami in $R A$ appear to be more common than had been recognised. The low grade nature of symptoms, the minimal effect on mobility, and the absence of significant trauma are typical features and suggest that many more stress fractures may go unrecognised.

(Ann Rheum Dis 1993; 52: 681-684)

Rehabilitation

Research Unit,

University of Leeds,

Leeds, United

Kingdom

A H Isdale

Correspondence to:

Dr A H Isdale,

Rheumatology and

Rehabilitation Research

Unit, University of Leeds, 36

Unit, University of Leeds, 36

9NZ, United Kingdom.

Accepted for publication

17 May 1993

Although stress fractures are a recognised occurrence in patients with rheumatoid arthritis (RA), the presentation may be insidious and as a consequence diagnostic delay and inappropriate treatment can result. Even in stress fractures of the arms and legs the swelling and pain may be mistaken for synovitis or sepsis, ${ }^{12}$ but in stress fractures of the pelvis the pain may also be mistaken for prosthetic loosening. ${ }^{3}$

As the stress fractures develop slowly, the initial radiographs are often negative. ${ }^{4-6}$ As healing occurs, resorption of bone around the fracture site may be mistaken for a malignant process. $^{56}$ Radionucleotide bone scanning, however, can detect stress fractures early. ${ }^{4} 7$

The feature of 22 patients with RA who developed stress fractures of the pubic rami are presented.

\section{Patients and methods}

The cases were collected over a four year period from patients receiving active rheumatological surveillance. Any patient with classical or definite RA who had sustained pubic rami fractures either as a new event or who was found serendipitously to have had such fractures was included. Information was obtained from the patients, their clinical notes, and radiological investigations.

\section{PATIENTS}

All 22 patients had classical or definite $R A$ with $20(91 \%)$ seropositive for rheumatoid factor. The mean (range) age was $68 \cdot 1(53-84)$ years and the mean disease duration was $24 \cdot 2(6-54)$ years. Ten $(45 \%)$ were Steinbrocker grade II, a further 10 grade III, and two (9\%) grade IV. Nineteen $(86 \%)$ were receiving prednisolone at a mean (range) daily dose of $6 \cdot 7(5-15) \mathrm{mg}$ for a mean duration of $12.4(1.5-26)$ years. The mean weight was $56.4(41-80) \mathrm{kg}$ with a mean body mass index of $26.6(17 \cdot 7-30 \cdot 1) \mathrm{kg} / \mathrm{m}^{2}$. Four patients were current smokers and five were ex-smokers. The exact age of menopause was not known in most patients. Two had had an oophorectomy, one at the age of 40 (fracture at the age of 72) and the other at the age of 46 (fracture at the age of 73). All patients had radiological evidence of osteoporosis and of the 16 with vertebral radiographs, $10(63 \%)$ had crush fractures. Six $(27 \%)$ patients had documented fractures elsewhere and in only one of these had there been significant trauma.

Calcium and phosphate levels were normal patients. Alkaline phosphatase was slightly increased in only three patients, but not all patients had this checked at the time of fracture. Parathyroid hormone and vitamin D levels were measured in two patients and were normal, and bone biopsy samples in another two patients were normal. Only one patient, who also had primary biliary cirrhosis, was 
Details of the presentation and radiological findings of pubic rami fractures in 22 patients with rheumatoid arthritis

\begin{tabular}{ll}
\hline Characteristics & No of patients \\
\hline Symptoms & \\
Low back pain & 9 \\
Groin pain & 6 \\
Hip pain & 4 \\
Pelvic pain & 3 \\
Leg pain & 2 \\
Knee pain & 1 \\
$\quad$ None & \\
Onset & 7 \\
$\quad$ Gradual & 12 \\
Acute/spontaneous & \\
Precipitating event & 12 \\
$\quad$ None & 7 \\
Fall to ground & 2 \\
Getting out of car & 1 \\
Getting out of bed & \\
Effect on mobility & 9 \\
$\quad$ None & 9 \\
Mild & 2 \\
Moderate & $1^{\star}$ \\
\hline Immobilised &
\end{tabular}

${ }^{\star}$ Multiple fractures.

receiving treatment for osteoporosis (calcium and etidronate).

\section{FRACTURES}

Pain was localised to the lower back, groin, or hip in 19 patients $(86 \%)$ (table). Three were asymptomatic and were found to have had fractures when the pelvis was radiographed for other reasons. Seven had a gradual onset and 12 had a spontaneous or acute onset of symptoms. Of these 12 , six were caused by falling to the ground, one by getting out of bed, and two by getting out of a car. Seven patients were radiographed at the onset of symptoms and the radiographs were negative in five. Three patients with negative radiographic results initially had bone scans and all were positive. All subsequent radiographs showed the fractures.

Three patients had total hip replacements and one patient had an Austin Moore prosthesis, but these procedures had no

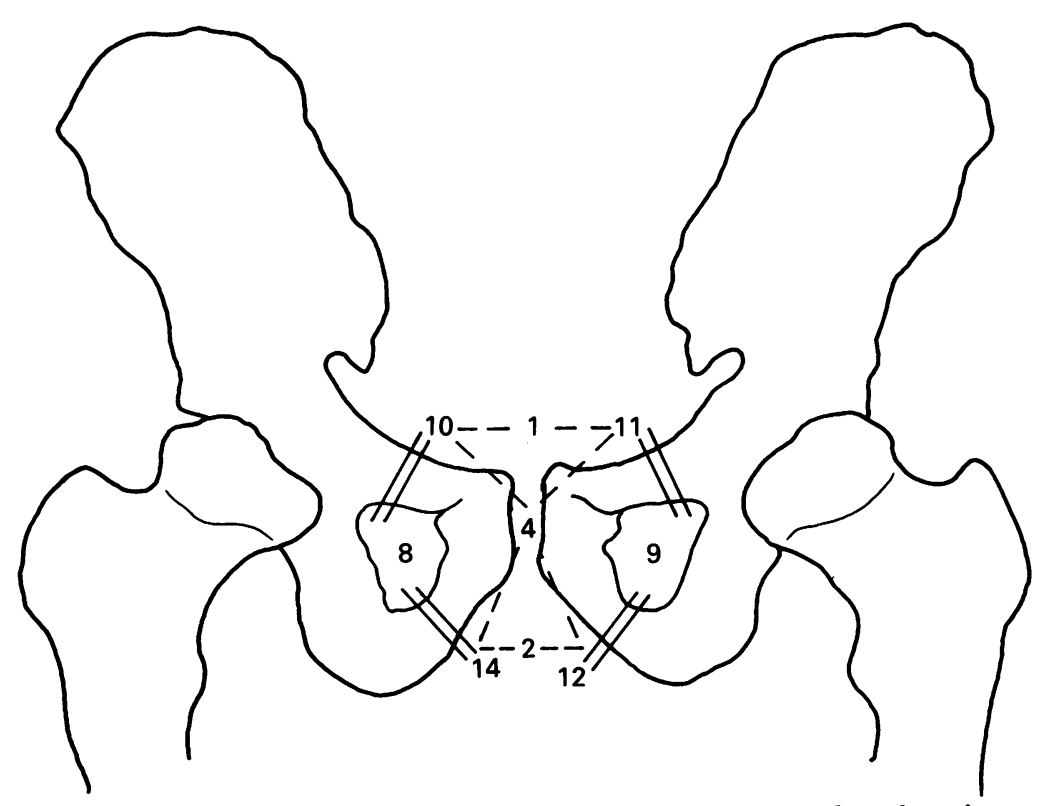

Figure 1 Diagramatic presentation of the pelvis showing fracture sites and numbers of fractures at each site. temporal relation with the fractures and there were no features to distinguish these patients from the others. Two had bilateral hip replacements; one of these patients had a fractured superior ramus and the other had fractured both inferior and one superior rami. One patient had a left hip replacement and a fractured right superior ramus, and the patient with a left Austin Moore prosthesis (fractured neck of femur four years previously) fractured both right rami and then both left rami within a few months.

The fractures affected all four pubic rami (fig $1)$. Twenty one fractures affected the superior rami and 26 the inferior rami. Twenty four fractures were on the right side and 23 on the left. Both rami on the left were fractured in nine patients and both on the right were fractured in eight patients. Four patients had a fracture in all four fami (fig 2). One patient had a fracture in three rami. Only two patients had a fracture in both inferior rami and one patient in both superior rami. Six had a single ramus fractured. One patient had a fracture of the right ilium in addition to both right rami caused by getting out of bed, and one patient fractured the right femoral neck and both right rami getting out of a car. One patient sustained fractures of the femur and humerus and both right pubic rami after being blown over by the wind. Seven patients had had previous long bone fractures. All but one patient made a successful recovery over two to four weeks with conservative management and gradual mobilisation in those with known fractures. The one patient who did not recover successfully had ununited long bone fractures. A malignant process was suggested on plain radiographs by lysis around the fracture site in two patients and another was thought to have a Looser zone. One patient had a biopsy sample taken before repeat radiographs showed the fracture.

\section{Discussion}

The occurrence of stress fractures in RA is recognised but most reports relate to fractures of the vertebrae or long bones, or both. Baer ${ }^{8}$ reviewed 1625 case records of patients with chronic arthritis in 1941. Fractures occurred in $1 \cdot 2 \%$, two thirds of whom had RA, and all were secondary to simple trauma. A population based study of fractures in patients with RA attending the Mayo clinic $^{9}$ identified 388 women who were followed up over a 25 year period (4902 person years). Sixty four had long bone fractures, 12 pelvic fractures (not specified), and 42 had one or more vertebral fractures. In contrast, fractures of the os pubis appear to be uncommon in RA. Godfrey et $a l^{5}$ reported five patients with RA with fractures of the os pubis. They reviewed reports published in English and found a further five cases. Since their review, three more have been reported. ${ }^{1011}$ Of these 13 cases, eight had fractures through the pubic rami.

Despite RA being more common in women, it is striking that all of the cases reported so far are women and most are post-menopausal, 


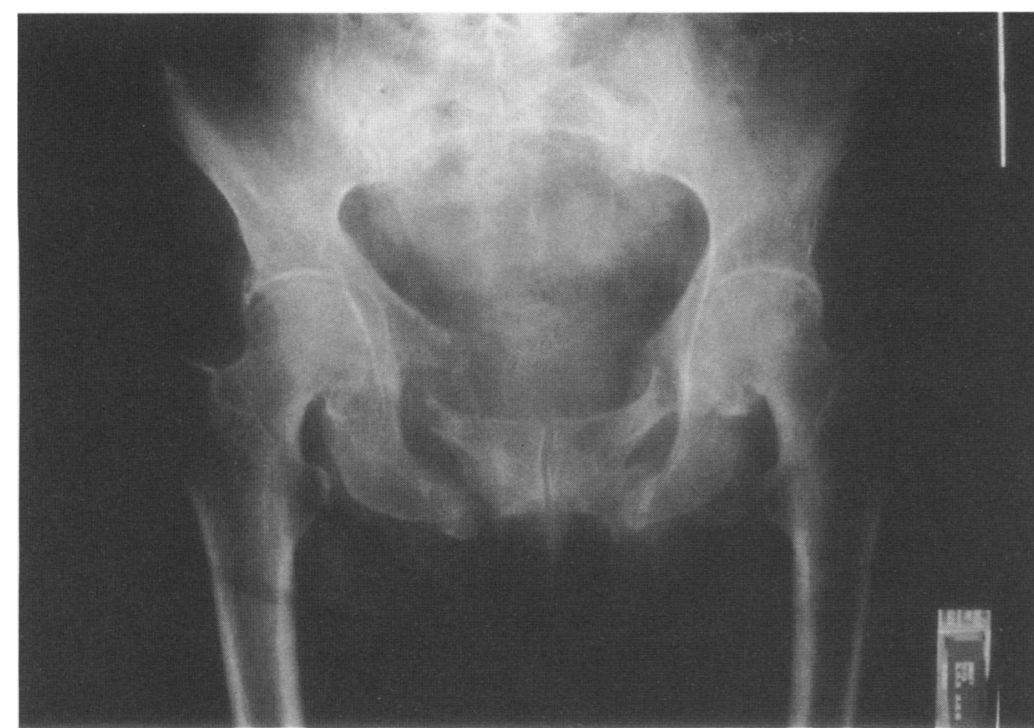

Figure 2 Plain radiograph of a 64 year old woman with $R A$ showing bilateral fractures of superior and inferior pubic rami. (march fractures). ${ }^{14}$ Arthroplasty may contribute to fatigue fracture, but this is relatively uncommon. McElfresh et al $^{15}$ looked at 5400 total hip replacements from the Mayo clinic over a 40 month period and found only three patients with fractures of the pubic rami. Two were spontaneous and the other was picked up radiographically five weeks after a fall. All three patients had osteoarthritis. Of the eight patients with $R A$ and pubic rami fractures, three had hip replacements with a further two from the present series. The data of McElfresh et al and the present series do not suggest that prosthetic material in the pelvis is a particular risk factor for pubic rami fracture. It is likely, however, that the pelvis is subjected to abnormal mechanical loads owing to the leg joints being affected by arthritis. In this series it is notable that it was unusual to have either both inferior or both superior rami or three rami fractured and relatively uncommon for only one ramus to fracture. This may suggest that these combinations generate more mechanical strain and other rami fracture as a result. It therefore seems likely that the stress fractures described are a combination of bone fatigue and insufficiency.

Importantly, these fractures occurred with little or no trauma. Vertical fractures through the ossification centres are characteristic. The usual history is of low back, hip, or groin pain, which in most patients does not prevent ambulation.

The poor initial detection rate of plain radiography ${ }^{1-7}{ }^{11}$ and the sensitivity of radionucleotide bone scans ${ }^{4-7}$ is well recognised and there should be little need for any further investigation with computed tomography or magnetic resonance imaging, despite their sensitivity and specificity. ${ }^{7}$ A potential problem with bone scans, however, is that uptake at the fracture site may be obscured by radionucleotide in the bladder. This occurred in one of our patients and in a patient reported by Godfrey et al. ${ }^{5}$ A second scan with a catheter in the bladder showed the fractures.

In the initial weeks after fracture bone resorption occurs and this may be mistaken for a primary or secondary malignant process, a Looser zone, or prosthetic loosening if the fracture involves the acetabulum in a replaced hip joint. ${ }^{56}$ Exuberant callous formation follows.

These fractures are probably much more common than is currently recognised but have a good outcome with conservative management. The possibility of a pelvic fracture should be considered in patients with RA presenting with spontaneous low back and pelvic pain and investigations should include serial plain radiographs and a bone scan.

I am grateful to my consultant colleagues who have allowed me to report their patients and to Mrs Barbara Dibb for typing. The Rheumatology and Rehabilitation Research Unit is grateful for the support of the Arthritis and Rheumatism Council. is distinct, clinical practice may not be. fracture of weak or abnormal bone with normal mechanical stresses. Fatique fracture is a fracture of normal bone which is subjected to repeated unaccustomed loading such as fractures of the inferior pubic ramus in new army recruits 
3 Cracchiolo A. Stress fractures of the pelvis as a cause of hip pain following total hip and knee arthroplasty. Arthritis Rheum 1981; 24: 740-2.

4 Geslien G E, Thrall J H, Espinosa J L, Older R A. Early detection of stress factures using ${ }^{99 m} \mathrm{Tc}$-polyphosphate. Radiology 1976; 121: 683-7.

5 Godfrey N, Staple T W, Halter D, Lorber A S. Insufficiency os pubis fractures in rheumatoid arthritis. $\mathcal{F}$ Rheumatol 1985; 12: 1176-9.

6 DeSmett A A, Neff J R. Pubic and sacral insufficiency fractures: clinical course and radiologic findings. $A m \mathcal{F}$

7 Lee J K, Yao L. Stress fractures: MR imaging. Radiology 1988; 169: 217-20.

8 Baer G J. Fractures in chronic arthritis. Ann Rheum Dis 1941; 2: 269-73.

9 Hooyman J R, Melton L J, Nelson A M, et al. Fractures after rheumatoid arthritis. Arthritis Rheum 1984; 27: 1353-61.
10 Tauber C, Geltner D, Noff M, Malkin C. Disruption of the symphysis pubis and fatigue fractures of the pelvis in a patient with rhematoid arthritis. A case report. Clin Orthop 1987; 215: 105-8.

11 Harris J M, Libbey C A. Stress fractures with normal activity in rheumatoid arthritis patients. Arthritis Rheum 1990; 33 (suppl 19): 151.

12 Beat A M, Bloch D A, Fries J F. Predictors of fractures in early rheumatoid arthritis. $\mathcal{F}$ Rheumatol $1991 ; 18:$ 804-8.

13 Laan R F J M, van Riel P L C M, van de Putte L B A. Bone mass in patients with rheumatoid arthritis. Ann Rheum Dis 1992; 51: 826-32.

14 Jones D B. March fractures of the inferior pubic ramus: a report of three cases. Radiology 1943; 41: 586-8.

$15 \mathrm{McElfresh}$ E C, Coventry M B. Femoral and pelvic fractures after total hip arthroplasty. $\mathcal{F}$ Bone foint Surg $[\mathrm{Am}] 1974$; 56: 483-92.

政

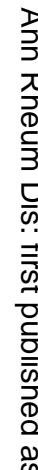

西

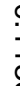

फ़

竞

ஸ̃

ஓ 